\title{
Representação social de adolescentes sobre saúde bucal
}

\author{
Social representation of teenagers about oral health \\ Representación social adolescente de la salud bucal \\ Tânia Adas SALIBA \\ Suzely Adas Saliba MOIMAZ \\ Fernando Yamamoto CHIBA \\ Renan Akira Fujii de OLIVEIRA \\ Alessandro Aparecido PEREIRA \\ Maria Lúcia Marçal Mazza SUNDEFELD \\ Nemre Adas SALIBA \\ Departamento de Odontologia Preventiva e Restauradora. Universidade Estadual Paulista (UNESP), Faculdade de Odontologia de Araçatuba \\ 16015 - 050 Araçatuba - SP, Brasil
}

\section{Resumo}

Introdução: A adolescência possui peculiaridades que merecem atenção diferenciada nos serviços de saúde. Objetivos: Compreender a percepção dos adolescentes sobre saúde bucal e identificar suas atitudes, espaços e comportamentos. Métodos: Pesquisa qualitativa com 44 adolescentes, de 12 a 17 anos, de escolas de bairros periféricos de um município paulista. Realizou-se entrevistas utilizando um roteiro de perguntas abrangendo enfoque social, afetivo e cognitivo, as quais foram gravadas e transcritas para análise, utilizando a metodologia do Discurso do Sujeito Coletivo. Resultados: As atividades de lazer mais referidas foram o esporte ou ficar em casa; os adolescentes consideram a escola um local para promoção de saúde; a estética tem grande importância; ter dentes bons foi aliado ao convívio social e profissional; e saúde bucal resumiuse a ter higiene e dentes limpos. Conclusão: A promoção de saúde para adolescentes pode refletir na saúde populacional em geral, pois serão adultos com compreensão da importância da prevenção, gerando uma sociedade saudável e com qualidade de vida.

Descritores: Comportamento do Adolescente; Saúde Bucal; Pesquisa Qualitativa; Educação em Saúde.

\section{Abstract}

Introduction: Adolescence has peculiarities that deserve different attention in health services. Objectives: Understand adolescents' perception of oral health and identify their attitudes, spaces and behaviors. Methods: Qualitative research with 44 adolescents, 12 to 17 years old, from schools in peripheral neighborhoods of a city in São Paulo. Interviews were conducted using a script of questions covering a social, affective and cognitive focus, which were recorded and transcribed for analysis, using the Collective Subject Discourse methodology. Results: The most mentioned leisure activities were sport or staying at home; teenagers consider the school a place for health promotion; aesthetics are of great importance; having good teeth was combined with social and professional life; and oral health was reduced to having clean teeth and hygiene. Conclusions: Health promotion for adolescents can reflect on population health in general, as they will be adults with an understanding of the importance of prevention, generating a healthy society and with quality of life.

Descriptors: Adolescent Behavior; Oral Health; Qualitative Research; Health Education.

\section{Resumen}

Introducción: la adolescencia tiene peculiaridades que merecen una atención diferente en los servicios de salud. Objetivos: Comprender la percepción de los adolescentes sobre la salud bucal e identificar sus actitudes, espacios y comportamientos. Métodos: Investigación cualitativa con 44 adolescentes, de 12 a 17 años, de escuelas en barrios periféricos de una ciudad de São Paulo. Las entrevistas se realizaron utilizando un guión de preguntas que cubren un enfoque social, afectivo y cognitivo, que se registraron y transcribieron para su análisis, utilizando la metodología del Discurso del sujeto colectivo. Resultados: Las actividades de ocio más mencionadas fueron el deporte o quedarse en casa; los adolescentes consideran que la escuela es un lugar para la promoción de la salud; la estética es de gran importancia; tener buenos dientes se combinaba con la vida social y profesional; y la salud oral se redujo a tener dientes limpios e higiene. Conclusión: La promoción de la salud para los adolescentes puede reflexionar sobre la salud de la población en general, ya que serán adultos con una comprensión de la importancia de la prevención, generando una sociedad saludable y con calidad de vida.

Descriptores: Conducta del Adolescente; Salud Bucal; Investigación Cualitativa; Educación en Salud.

INTRODUÇÃO

Os adolescentes constituem cerca de $20 \%$ da população mundial e $85 \%$ são de países em desenvolvimento ${ }^{1}$. Mesmo com a desaceleração do ritmo de crescimento da população de jovens, esta geração é a mais numerosa em toda a história do Brasil, representando um total de 51.429.397 pessoas, aproximadamente $30,3 \%$ da população brasileira, sendo 35.287 .882 adolescentes e 16.141.515 jovens ${ }^{2}$.

A atenção direcionada aos adolescentes é essencial e o profissional da saúde deve estar preparado para enfrentar os desafios de lidar com esses pacientes, integrando vários fatores como família, ambiente comunitário, cultura e crenças $^{3}$. Os serviços de saúde para adolescentes são cada vez mais reconhecidos como prioritários em populações de baixa e média renda, enfatizando a necessidade de investigar os fatores que poderiam ampliar ou melhorar a atuação desses serviços em relação a estes indivíduos ${ }^{4}$.

O foco neste grupo populacional mostrase cada vez mais necessário, pois nesta etapa da vida ocorrerá a construção de valores que guiarão a vida adulta ${ }^{5}$. A partir do conhecimento científico, crianças e adolescentes podem chegar à fase adulta sem experiência de cárie, por meio de programas que privilegiem a prevenção e promoção de saúde. Neste sentido, destaca que o processo de educação envolve principalmente mudança de comportamento, sendo importante detectar os pontos favoráveis e as dificuldades neste processo, sem perder de vista as responsabilidades da equipe de saúde, comunidade e entidades governamentais ${ }^{6}$. 
Os jovens demostram uma elevada resistência em se aproximar dos serviços de saúde e estes têm dificuldades em acolher os adolescentes que os procuram ${ }^{7}$. A Organização Mundial da Saúde tem dedicado atenção especial aos programas de promoção de saúde nas escolas e tem tratado a educação em saúde bucal como uma questão importante que deve ser desenvolvida para diminuir a prevalência de doenças bucais ${ }^{8}$. A dor relacionada às más condições de saúde bucal pode ter efeito considerável sobre o desempenho das crianças e adolescente na escola, além de influenciar a qualidade de vida e seu sucesso na vida adulta ${ }^{8}$.

O objetivo nesta pesquisa foi compreender a percepção dos adolescentes sobre saúde bucal e identificar suas atitudes, espaços e comportamentos com o intuito de auxiliar o planejamento de ações educativas para esse grupo etário.

\section{MATERIAL E MÉTODO}

Trata-se de uma pesquisa qualitativa realizada em adolescentes na faixa etária de 12 a 17 anos, estudantes de duas escolas públicas localizadas em bairros da periferia de um município do Estado de São Paulo.

Realizou-se uma amostragem por conveniência, de modo que a amostra foi composta por 44 adolescentes que aceitaram ser entrevistados, sendo 21 da Escola A e 23 da Escola B.

A coleta de dados foi realizada por meio de entrevista semiestruturada, utilizando um roteiro de perguntas, previamente testado em um estudo piloto, abrangendo enfoque social, afetivo e cognitivo, como descrito abaixo.

- Enfoque social: "Quais suas atividades de lazer?"; "Quais assuntos mais interessam a você?"; "Onde você conversa sobre assuntos de seu interesse?"; "O que sua escola poderia fazer por você em relação à saúde bucal?".

- Enfoque Afetivo: "Ter bons dentes influencia na vida das pessoas? De que forma?"; "Você dá menos valor para uma pessoa que tem dentes feios?"; "Você namoraria uma pessoa com dentes estragados? Por que?".

- Enfoque cognitivo: "Você já participou de palestras sobre saúde bucal? O que achou?"; "Você tem paciência para ficar numa palestra sobre saúde bucal?"; "Que atividades mais o incentivaria a aprender sobre saúde bucal?"; "O que é ter saúde bucal para você?".

As entrevistas foram gravadas $e$ transcritas fielmente. A análise dos dados foi realizada utilizando o Discurso do Sujeito
Coletivo (DSC); por meio desta estratégia metodológica foi possível reconstruir com pedaços de discursos individuais, como em um quebra-cabeças, tantos discursos síntese se julgue necessário para expressar dada figura, ou seja, um dado pensar ou representação social sobre um fenômeno ${ }^{9}$.

Para organizar e tabular os depoimentos foram utilizadas as figuras metodológicas expressões-chave, ideia central (IC) e o discurso do sujeito coletivo. A comparação entre as duas escolas, de acordo com as frequências das ideias centrais de cada uma, foi realizada utilizando o Teste Qui-quadrado ou Teste Exato de Fisher, adotando o nível de significância de $5 \%$. O estudo foi aprovado pelo Comitê de Ética em Pesquisa (processo no 200301539) e conduzido de acordo com as normas da Resolução no 466/2012 do Conselho Nacional de Saúde. Foram obtidas as autorizações dos dirigentes de ensino responsáveis pelas escolas, dos responsáveis legais por meio do Termo de Consentimento Livre e Esclarecido e dos adolescentes por meio do Termo de Assentimento Livre e Esclarecido.

RESULTADOS E DISCUSSÃO

Entrevistou-se 21 adolescentes na Escola A, sendo $66,7 \%$ do sexo masculino e $33,3 \%$ feminino, enquanto na Escola $B$ foram estudados 23 adolescentes, sendo $52,2 \%$ do sexo masculino e $47,8 \%$ feminino. Seguem os discursos dos entrevistados, de acordo com o enfoque abordado.

- Enfoque social

Não houve diferença estatisticamente significativa ( $p$-valor $=0,8179$ ) entre as ideias centrais para a questão "quais suas atividades de lazer?", assim, optou-se por apresentar um único discurso abrangendo as entrevistas dos 44 adolescentes.

- Discurso do Sujeito Coletivo (DSC 1) $(\mathrm{IC}=\mathrm{A})$ "...Tem um campinho aqui perto e eu gosto de jogar futebol. Tem um vizinho que mora perto de casa que tem um time de futebol, eu pratico esporte com ele. Ainda nado no Termas, jogo vôlei, handebol. Também gosto de brincar na rua, andar de bicicleta, tocar na fanfarra, ouvir música..."

(IC=B) "...Na semana eu vou a Fundação Mirim, aí eu chego em casa, fico em casa não saio, porque é muito corrido pra mim. Ah, eu fico em casa, jogando vídeo game, assistindo televisão, vou para casa de amigas e eu também tenho que cuidar da minha casa..." $(\mathrm{IC}=\mathrm{C})$ "... No final de semana às vezes eu saio com os colegas, vou na casa da minha vó..." $(\mathrm{IC}=\mathrm{D})$ "...Aqui no bairro não tem muita coisa, 
só tem escola, não tem uma coisa pra galera se reunir, conversar, quer dizer, quase não tem nada de lazer né. Não tem um espaço, uma pracinha, não tem nada..."

As duas atividades mais referidas foram a prática de esporte ou ficar em casa. O trecho "...não tem muita coisa, só tem escola...", demonstra a ausência de políticas públicas essencial para formação do cidadão e justifica a opção ficar em casa. A participação em atividades esportivas pode contribuir para desenvolver a socialização, o respeito pelo grupo, o aprendizado de normas e regras, diminuir a exposição à violência e ao uso de drogas, além de propiciar o desenvolvimento físico e mental, estimulando o espírito comunitário, mudanças de estilos de vida, criatividade e a formação da personalidade do jovem $^{10,11}$.

Os trechos "...vou para casa de amigas..." e "...saio com minhas colegas...", demonstra a influência dos amigos. A amizade entre adolescentes é uma maneira de afirmação e integração. Os adolescentes buscam a segurança no grupo de amigos, pois este é referência para o jovem que está constituindo sua identidade, a partir de uma série de mudanças corporais e emocionais que vem sofrendo ${ }^{12}$.

A música e a televisão exercem grande influência na vida dos jovens; nesta fase é muito comum ficarem horas trancados no quarto ouvindo música, interessando-se muitas vezes mais pelo ritmo, quando é envolvente, do que pelas letras ${ }^{13}$. Os programas televisivos voltados para essa faixa etária são poucos e mostram uma realidade distante da maioria dos jovens, além de não explorem o lado educativo, e imporem o que os jovens vão vestir, ouvir ou consumir $^{14}$. Notou-se a ausência da prática da leitura de livros, possivelmente por ser uma forma de lazer que demanda considerável esforço e tempo, além de disputar com outras atividades mais valorizadas, como 0 entretenimento com equipamentos eletrônicos ${ }^{15}$.

Sobre a questão "quais assuntos mais interessam a você", emergiram sete ideias centrais entre as entrevistas realizadas em cada uma das escolas. Não houve diferença entre as ideias centrais das duas escolas ( $p$ valor $=0,5497$ ), portanto os discursos foram unificados.

- Discurso do Sujeito Coletivo (DSC 2) $(\mathrm{IC}=\mathrm{A})$ "...Ah tem vários né. Na hora inventa assunto. Eu gosto de falar de futebol. Quando passa um jogo nós fala do jogo, do lance, o que aconteceu e aí fica discutindo..."
(IC=B) “...Tem coisas que é particular não dá pra falar. Mulher, por exemplo. A gente conversa muito sobre meninas, é o forte né, Sobre balada, sexo, família também, amigos, vídeo game, essas coisas..."

$(\mathrm{IC}=\mathrm{C})$ "...A gente conversa sobre filme..." (IC=D) “...também gosto de falar de carro..." $(\mathrm{IC}=\mathrm{E})$ "...da escola..."

$(\mathrm{IC}=\mathrm{F})$ "...sobre música, das brigas que acontecem..."

$(\mathrm{IC}=\mathrm{G})$ "...Sobre nós mesmo, sabe, nossa vida, né, futuro, pra frente, o que vai ser na vida. Ah, sobre religião, sobre igreja. O meu assunto é sobre Jesus. Essas coisas que menina conversa, de lugares que a gente quer sair, sobre roupa, essas coisas..."

A descoberta da sexualidade é uma característica marcante dessa fase, de modo que programas educativos voltados para esse grupo devem abordar essa questão. Aproximadamente $25 \%$ de todas as doenças sexualmente transmissíveis são diagnosticadas em jovens com menos de 25 anos. Neste sentido, mais ações de prevenção devem ser desenvolvidas, com a participação de setores governamentais, não-governamentais, escolas, serviços de saúde e comunidade ${ }^{16}$.

A presença da religião no discurso reforça a necessidade de alguns adolescentes em sustentar sua vida em torno da fé na religião, visto que é por meio dela que conseguem as forças necessárias para poder seguir no caminho certo e conseguem ser amados $^{14}$.

Observou-se também a preocupação com a violência, "...sobre as brigas que acontecem...". No Brasil, as causas externas apresentam-se como agravos de maior impacto na morbimortalidade de adolescentes, com tendência crescente na mortalidade relacionada à violência a partir dos 15 anos $^{17}$.

Sobre a questão "onde você conversa sobre assuntos de seu interesse?", somente as ideias centrais escola, casa e rua surgiram como resposta. Não houve diferença estatística significativa entre as escolas ( $p$ valor $=0,0621$ ) e os discursos foram unificados.

- Discurso do Sujeito Coletivo (DSC 3) $(\mathrm{IC}=\mathrm{A})$ "...Em casa mesmo, na casa dos colegas. Às vezes uma vai na casa da outra conversa. Tem vez que eles vão na minha casa me chamar, aí a gente senta lá frente, na calçada fica conversando. Daí dá umas 7 horas e começa a chegar amigo meu. Fica tocando violão, conversando. Ah a gente se encontra também na escola, no período de aula, no intervalo..." 
(IC=B) “...Aí na escola mesmo a gente conversa, na sala de aula..."

$(\mathrm{IC}=\mathrm{C})$ "...Quando eu estou na rua assim, com a turma, a gente começa a puxar assunto e conversa lá na rua mesmo. E tem vez que ali na quadra do bairro..."

Os discursos confirmam a falta de opções de lazer e convivência para este grupo populacional. $\mathrm{O}$ adolescente tem necessidade de companhia e amizade, de jovens da mesma idade, que tenham interesses e aspirações similares, por isso se mostram habitualmente alegres e gostam de agitação quando estão reunidos na escola ${ }^{18,19}$.

$\mathrm{Na}$ questão "o que sua escola poderia fazer em relação à saúde bucal?", não houve diferença estatisticamente significante ( $p$ valor $=0,6571)$ e por isso apresenta-se um discurso englobando os entrevistados das duas escolas. Notou-se que, pela primeira vez, dois entrevistados responderam "não sei", sugerindo aparente desinteresse pelo assunto.

- Discurso do Sujeito Coletivo (DSC 4) $(\mathrm{IC}=\mathrm{A})$ "...Deveria ter atividades ligadas a escovar os dentes, dar mais palestras aqui na escola, mas pra todo mundo, não só para algumas salas. Porque muita gente nem sabe escovar os dentes direito e se vem alguém falar sobre isso, já ta resolvendo um pouco do problema..."

(IC=B) "...Acho também que deveria ter dentista, porque aqui não tem, aqui eles só passam flúor na boca da gente. Porque ultimamente não ta tendo tanto, tão falando mais sobre AIDS..."

$(\mathrm{IC}=\mathrm{C})$ "... O Professor de ciência falar na matéria, trazer também aquelas bocas..."

$\mathrm{IC}=\mathrm{D})$ "...Passar vídeo sobre os dentes..."

$(\mathrm{IC}=\mathrm{E})$ "... Não ter muito doce para vender. Eu acho com certeza que seria melhor..."

$(\mathrm{IC}=\mathrm{F})$ “...Ah, eu não sei não..."

Os discursos reforçam a prioridade que - serviço público de saúde promove aos escolares na faixa etária até 12 anos. Essa situação reflete nos indicadores de saúde bucal; os resultados do último levantamento epidemiológico nacional mostram que na faixa etária de 15 aos 19 anos cerca de $90 \%$ dos indivíduos apresentam pelo menos um dente permanente com experiência de cárie, enquanto aos 12 anos diminui para $70 \%{ }^{20}$.

Para os adolescentes a escola é um local adequado para promoção de saúde, um local privilegiado para o desenvolvimento de ações de educação em saúde, permitindo que se desenvolva estilos de vida saudáveis e condutas de baixo risco ${ }^{21}$. Neste sentido, destaca-se a necessidade de sensibilização e capacitação de professores para abordarem a questão saúde/trabalho dentro da escola, com desenvolvimento de metodologias educativas apropriadas a cada realidade social ${ }^{22}$.

- Enfoque afetivo

Em relação à questão "ter bons dentes influencia na vida das pessoas? De que forma?", não houve diferença estatística significativa entre as escolas ( $p$-valor $=0,3266$ ), desse modo, seguem os discursos das duas escolas agrupados em um.

- Discurso do Sujeito Coletivo (DSC 5)

$(\mathrm{IC}=\mathrm{A})$ "...Influencia e ajuda bastante. Porque você vai ta sempre olhando pra pessoa e o cara ter higiene bucal boa conta muito, fica mais bonito, atrai mais as pessoas, ajuda a namorar, é o cartão de visita dela..."

(IC=B) "...Na presença da pessoa a estética é tudo, é como a pessoa se veste, como a pessoa. E também o aspecto da pessoa muda né. Quando você olha você vai ver o conjunto inteiro e o dente influencia também. Se a pessoa tem o dente bom, toda hora que ela vai conversar, dá risada, influencia um pouco. Agora se ele não tem o dente bom, tem o dente estragado, ele fica meio preocupado em às vezes abrir a boca e a pessoa ver. $E$ quando você quiser arrumar uma namorada, ela vai querer tirar você ou se alguém fica com uma menina e não tem o hálito bom e ai se ferra..."

$(\mathrm{IC}=\mathrm{C})$ “...Não tendo o dente podre, pode ter uma vida melhor, ajuda a arrumar emprego Tipo você vai pro serviço de cabelo bagunçado, sem fazer barba e o outro vai alinhado, o cara vai dar o serviço pra ele. E o cara ter higiene bucal boa conta muito nessa hora. é. Ter os dentes bons dá uma boa impressão pra pessoa, fica mais higiênica, mais cuidadosa, vai ter um sorriso mais bonito. Se você tem os dentes bons, você tem uma namorada, ela vai gostar de seus dentes, da boca limpa. Mas se você tiver os dentes amarelos o sorriso fica mais feio..."

$(\mathrm{IC}=\mathrm{D})$ "...Tem gente que diz que não, que depende do caráter da pessoa..."

(IC=E) “...Não sei...”

Influenciada pela mídia, a geração atual preocupa-se demasiadamente com a aparência e a estética. Nos discursos, os jovens aliam ter dentes bons ao relacionamento com as pessoas, à conquista de um(a) namorado(a) e inserção no mercado de trabalho. Assim, destaca-se a necessidade de envolver em programas de saúde voltados para adolescentes, os diferentes aspectos de interesse presentes no cotidiano e no contexto que estão inseridos ${ }^{23}$. 
Em relação à questão "você dá menos valor para uma pessoa que tem dentes feios?", unificou-se o discurso das duas escolas, pois não houve diferença estatística significante ( $p$ valor $=0,5062$ ).

\section{- Discurso do Sujeito Coletivo (DSC 6)} $(\mathrm{IC}=\mathrm{A})$ "...Que nada, por causa de dente podre? Eu acho que não. Eu sou legal com todo mundo. Porque que não é pelos dentes que você deve tratar, eu sei que é fundamental, mas também não é assim. Eu trato tudo igual, nem reparo. E meu dente também não é tão bonito assim. Mas as vezes sim. Tipo o dente mal tratado, dente feio mano, estraga tudo. E depende da pessoa se for amigo não. Porque amigo é amigo..."

$(\mathrm{IC}=\mathrm{B})$ "...Agora vamos supor uma pessoa que não conheço, já vou ficar com um pouco de receio. A pessoa que tem dente feio fica meio discriminada da turma, ninguém vai gostar dela. As pessoas têm um pouco menos de consideração, deixa meio afastado, não conversa muito..."

$(\mathrm{IC}=\mathrm{C})$ "...A gente não vai excluir, trata normal, mas só que é feio. Não é que a gente dá menos valor para essas pessoas. Mas as pessoas que tem os dente mais cuidado elas ficam mais vistas pelas outras pessoas do lado de lá, de alto nível. E com as pessoas mais pobre convive normalmente..."

(IC=D) “...Não sei..."

Os discursos mostram que na rotina diária com os amigos, os adolescentes convivem normalmente com os pares considerados com "dentes feios", entretanto, nota-se a imposição da importância da estética e beleza no trecho "... as pessoas que tem os dente mais cuidado elas ficam mais vistas pelas outras pessoas do lado de lá, de alto nível...".Estudo sobre representações sociais de saúde bucal verificou que a estética é um importante fator de saúde bucal e a aparência dos dentes é relevante no convívio social, pois as pessoas são classificadas quanto à aparência, habilitando-as ou não para o mercado de trabalho ${ }^{5}$.

A análise das questões "você dá menos valor para uma pessoa que tem dentes feios?" e "você namoraria uma pessoa com dentes estragados?" surpreendeu pela inversão de valores expressos pelos adolescentes. A afirmação de que não daria menos valor para uma pessoa que tem dentes feios, correspondendo a 28 adolescentes, pode ser considerado um pensamento de aceitação do outro, enquanto a resposta de que não namoraria uma pessoa com dentes estragados pode ser considerada uma rejeição do outro, totalizando 32 adolescentes. Desprezando opiniões indecisas e considerando somente total aceitação e total rejeição, comprovou-se as duas opiniões inversas de posicionamento dos adolescentes frente a essas situações, aceito como amigo, mas não aceito como namorado ( $p$-valor $<0,0001$ ).

- Discurso do Sujeito Coletivo (DSC 7) $(\mathrm{IC}=\mathrm{A})$ "...Não. Porque se ela não cuida dos dentes, estraga tudo, dente é essencial. Eu ia ter nojo de beijar, como que eu vou beijar a boca dessa pessoa, é uma porquice, falta de higiene. Deus me livre. Por causa do hálito também, eu não iria querer e eu ia ficar com nojo. E tem o aspecto da cárie, se tem o dente podre eu acho que pode passar pra mim e eu pegaria bactéria. Se ela conhece as forma de prevenção, você olha assim ela é burra, não tem higiene..."

(IC=B) “...Aí eu não sei. Porque eu não vou namorar ela porque o rosto é bonito. Eu vou vê se ela é uma amiga assim, se é confiável..."

$(\mathrm{IC}=\mathrm{C})$ "... Sim, eu namoraria, mas mandaria ela ir ao dentista para consertar os dentes. Não é por causa do dente que eu vou namorar..."

$(\mathrm{IC}=\mathrm{D})$ “...Ah depende né..."

Os adolescentes consideram 0 autocuidado com os dentes é um fator primordial no relacionamento com o sexo oposto. O trecho "...se ela conhece as forma de prevenção, você olha assim ela é burra, não tem higiene..." mostra a concepção que muitos serviços e profissionais de saúde tem diante do fracasso ou falta de motivação dos indivíduos frente às ações educativas. Por falta de resultados, atribui-se aos usuários dos serviços de saúde a incapacidade de compreender e de agir segundo normas estabelecidas, entretanto, não basta ter conhecimento para modificar a forma de viver, é preciso ter condições para realizar a mudança ${ }^{24,25}$.

- Enfoque cognitivo

Não houve diferença significativa ( $p$ valor $=0,7010$ ) entre os discursos referentes à questão "você já participou de palestras sobre saúde bucal? O que achou?", deste modo, tem- se um discurso englobando as duas escolas.

- Discurso do Sujeito Coletivo (DSC 8)

$(\mathrm{IC}=\mathrm{A})$ "...Muita gente não valoriza, mas esclarece bastante muitas perguntas que você faz. Não nunca participei..."

$(\mathrm{IC}=\mathrm{B})$ “...Eu já e achei legal, interessante. É bom porque a gente aprende como escova melhor e você pode aprender um pouquinho sobre o que a pode fazer, que a gente tem que 
escovar, que tem vários tipos de bactérias. Incentiva bastante a cuidar da saúde bucal e aprender mais sobre a boca, os dentes. Eles falavam como que escova os dentes, eles tinham um negócio tipo uma dentadura e eles mostravam, achei bacana.

$(\mathrm{IC}=\mathrm{C})$ "...Olha, eu não me lembro, acho que não. Em casa a minha mãe mesmo fala, olha vai escovar os dentes. Agora meu irmão não liga muito pra dente né. Eu não, eu escovo. ".

Nos discursos observa-se que os adolescentes consideram a educação em saúde bucal por meio de palestras um importante instrumento para mudança de comportamento e atitudes em relação à saúde bucal, entretanto, para atingir esse objetivo é fundamental que o profissional de saúde tenha métodos eficientes, pois além de lidar com as questões biológicas, têm que ter competência na esfera comportamental ${ }^{26}$.

Para a pergunta "você tem paciência para ficar numa palestra sobre saúde bucal?", observou-se que seis adolescentes que na questão anterior responderam não ter assistido a nenhuma palestra, neste momento afirmaram que teriam paciência para assistir. Nesta questão os discursos foram separados, um para cada escola, pois houve diferença estatística significativa ( $p$-valor $=0,0217)$.

- Discurso do Sujeito Coletivo (DSC 9) Escola A $(\mathrm{IC}=\mathrm{A})$ "...Eu tenho porque eu gosto de ver, de aprender as coisas entendeu. Ver a pessoa explicando como é..."

(IC=B) "..... Pra falar a verdade não, demora muito e não tenho paciência de ficar assistindo. Eles batem sempre na mesma tecla, às vezes irrita um pouco. Porque é sempre aquela coisinha decorada sabe? Vem sempre a mesma coisa. Eu sei de cor já. $(\mathrm{IC}=\mathrm{C})$ "..... Tem vez que tenho. Quando eunão tenho, aí eu nem escuto. Porque fala muito e eu não sou muito de ficar ouvindo.

- Discurso do Sujeito Coletivo (DSC 10) Escola B “...Tenho. Às vezes eu tenho. Aqui também passa o filme pra gente ver, porque palestra eu não gosto muito, é muito chato....".

$\mathrm{Na}$ Escola $\mathrm{A}$, notou-se mais entusiasmo ao responder essa questão, por outro lado na Escola $\mathrm{B}$, uma única frase representou todos os entrevistados, pois a maioria dos discursos foi monossilábicos: "tenho", "sim" ou "teria". Observou-se que apesar do trecho "...eu tenho porque eu gosto de ver...", sobressai a visão de que a palestra é algo cansativo. Frequentemente, culpa-se os adolescentes pelo desinteresse por atividades educativas, entretanto, muitas vezes é o profissional que não está preparado para trabalhar com essa faixa etária. Deve-se preocupar em dar maior ênfase às necessidades dessa fase e não somente no aspecto cognitivo ${ }^{27}$.

$\mathrm{Na}$ questão "que atividade mais o incentivaria a aprender sobre saúde bucal?", os discursos foram agrupados em somente um, pois não houve diferença estatística significante ( $p$-valor $=0,4674)$.

- Discurso do Sujeito Coletivo (DSC 11) $(\mathrm{IC}=\mathrm{A})$ "...Poderia ter mais palestra do que tem, pode ser aqui na escola, mas não falar muito só o que deve falar mesmo..."

(IC=B) “...Ah sei lá, só explicando não dá. Eu acho que deveria trazer coisa uma mais dinâmica, entendeu? Que a gente possa participar também, não ficar sentado olhando para cara do palestrante lá que ta falando. Porque só ficar falando a gente não entende nada, tem que mostrar, eu quero ver tudo o que está fazendo, ficar de frente e ta vendo..." $(\mathrm{IC}=\mathrm{C})$ "...E a professora falar mais na sala de aula, usar vídeo, jornalzinho, a televisão, ter música. Vou citar alguns exemplos. Se não tiver paciência não aprende nada. Eu acho que eu preciso ver primeiro, eu preciso ver para eu entender melhor as coisas. Tem que ter algo que não prende a pessoa num trem só, que diversifica..."

$(\mathrm{IC}=\mathrm{D})$ "...Eu vendo e aprendendo eu posso passar para outras pessoas, eu tenho paciência .... Devia ser desse jeito, teatro, peças infantis ter um papo que despertasse, isso eu quero prestar atenção porque eu achei bacana..."

$(\mathrm{IC}=\mathrm{E})$ "...Agora vem sempre com uma má vontade, aí até desanima. Vir um dentista na escola para falar sobre essas coisas, olhar, explicar com imagem..."

$(\mathrm{IC}=\mathrm{F})$ "...Ah, eu não sei..."

......relato" dos entrevistados mostra a necessidade de envolvê-los diretamente nas atividades educativas, reforçando que programas educativos em saúde bucal que aplicam metodologia participativa têm fundamental importância na mudança de hábitos em adolescentes, independentemente de sua inserção social ${ }^{28}$.

A análise da questão "o que é ter saúde bucal para você?" demonstrou que não houve diferença estatisticamente significativa ( $p$ valor $=0,2067$ ), portanto tem-se um discurso abrangendo as duas escolas.

- Discurso do Sujeito Coletivo (DSC 12) $(\mathrm{IC}=\mathrm{A})$ "...Para mim é cuidar da boca, dos dentes, escovar os dentes direitinho, não só os dentes, mas a língua. É ter higiene..."

(IC=B) “...Ter os dentes bonitos, limpos, branquinho, ser alegre..." 
$(\mathrm{IC}=\mathrm{C})$ “...E também ter higiene, um bom hálito, os dentes bonitos, não ter os dentes estragados, podres..."

$(\mathrm{IC}=\mathrm{D})$ "...Não ter cárie. Acho que tem pessoa que não liga, acham que é só para comer e pronto, não limpa e não faz nada. É ter cuidado com a saúde, cuidar do corpo, da alimentação e cuidar bem dos dentes, escovar os dentes direito..."

$(\mathrm{IC}=\mathrm{E})$ "... Sempre ir ao dentista..."

Nos discursos dos adolescentes observou-se que a saúde bucal se resume somente a ter higiene e dentes limpos. O trecho “...É ter cuidado com a saúde, cuidar do corpo, da alimentação..." mostra que os adolescentes são capazes de relacionar a saúde geral com a saúde bucal.

Os relatos mostram que os adolescentes consideram que a cárie dentária pode ser evitada por meio do autocuidado e da visita ao cirurgião-dentista, sugerindo que o aparecimento da doença e a busca pela saúde parecem ser atribuição e responsabilidade apenas do indivíduo. A realização de atividades educativas, utilizando um modelo problematizador e que consiga desenvolver um elo entre o trabalho de cuidar e os aspectos sociais, pode ser uma solução para esse aspecto $^{5}$.

Diante da riqueza de informações obtidas nos discursos dos adolescentes notase que a promoção de saúde para esta faixa etária pode refletir de forma significativa na saúde populacional em geral, pois além de levar o aprendizado para os meios sociais em que vivem, serão os futuros adultos e idosos com capacidade de compreensão da importância da prevenção, gerando com o passar do tempo um sociedade saudável e com qualidade de vida.

\section{CONCLUSÃO}

Os adolescentes demonstraram grande preocupação com a estética e consideraram importante 0 cuidado com os dentes nos relacionamentos sociais e profissionais, destacando o papel da escola como um meio para melhoria nas condições de saúde bucal e enfatizando a necessidade de atividades na quais possam participar ativamente. Encontros de grupos para conversar na rua, na escola ou em casa reforçaram a necessidade de companhia e amizades, entretanto, uma parcela considerável relatou ficar em casa, assistindo televisão ou ouvindo música, demonstrando a ausência de espaços de lazer na região.

\section{REFERÊNCIAS}

1. Chilinda I, Hourahane G, Pindani M, Chitsulo C,
Maluwa A. Attitude of health care providers towards adolescent sexual and reproductive health services in developing countries: a systematic review. Health. 2014;06:1706-13

2. Brasil. Ministério do Planejamento, Orçamento e Gestão. Censo Demográfico 2010. Características da população e dos domicílios. Resultados do universo. Instituto Brasileiro de Geografia e Estatística - IBGE. 270p.

3. da Silva MG, Monteiro ARM, Barros KM, Feitoza SMS, Braga VAB, Rebouças CBA. Mental health care given to children and adolescents in the center for children and your psychosocial: From the perspective of health professionals. Health 2015;7:696- 703.

4. James S, Pisa PT, Imrie J, Beery MP, Martin C, Skosana C, Delany-Moretlwe S. Assessment of adolescent and youthfriendly services in primary healthcare facilities in two provinces in South Africa. BMC Health Serv Res. 2018; 18(1):809.

5. Abreu MHNG, Pordeus IA, Modena CM. Representações sociais de saúde bucal entre mães no meio rural de Itaúna (MG), 2002. Ciênc saúde coletiva. 2005;10(1):245-59.

6. Horowitz AM. The public's oral health: the gaps between what we know and what we practice. Adv Dent Res. 1995;9(2):91-5.

7. Taddeo D, Egedy M, Frappier JY. Adherence to treatment in adolescents. Paediatr Child Health. 2008;13(1):19-24.

8. Veiga NJ, Pereira CM, Ferreira PC, Correia IJ. Oral health behaviors in a sample of portuguese adolescents: an educational issue. Health Promot Perspect. 2014;4(1):35-45.

9. Lefevre F, Lefevre AMC. Discurso do sujeito coletivo: representações sociais e intervenções comunicativas. Texto contexto - enferm. 2014; 23(2):502-7.

10. Ghildiyal R. Role of sports in the development of an individual and role of psychology in sports. Mens Sana Monogr. 2015;13(1):165-70.

11. Qin C, Hao Z, Zhang T, Guo Y. Correlation study of sports lifestyle and physical health about college students. Open J Soc Sci. 2016; 4:104-10.

12. Schoen-Ferreira TH, Aznar-Farias M, Silvares EFM. A construção da identidade em adolescentes: um estudo exploratório. Estud Psicol (Natal). 2003;8(1):107-15.

13. Boer D, Abubakar A. Music listening in families and peer groups: benefits for young people's social cohesion and emotional well-being across four cultures. Front Psychol. 2014;5:392.

14. Martins PO, Trindade ZA, Almeida AMO. O ter e o ser: representações sociais da adolescência entre adolescentes de inserção urbana e rural. Psicol Reflex Crit. 2003;16(3)555-68.

15. Oliveira MFC, Bzuneck JA, Rufini SE. Motivação de adolescentes para leitura: estudo com a abordagem centrada na pessoa. Psicol Educ. 2017; 45:67-76.

16. Martins LB, da Costa-Paiva LH, Osis MJ, de Sousa MH, Pinto-Neto AM, Tadini V. Fatores associados ao uso de preservativo masculino e 
ao conhecimento sobre DST/AIDS em adolescentes de escolas públicas e privadas do Município de São Paulo, Brasil. Cad Saúde Pública. 2006;22(2):315-23.

\section{CONFLITO DE INTERESSES}

Os autores declaram não haver conflitos de interesse

AUTOR PARA CORRESPONDÊNCIA

Prof. Dr. Fernando Yamamoto Chiba

Faculdade de Odontologia - Câmpus de Araçatuba

Rua José Bonifácio, 1193

16015-050 - Araçatuba - SP, Brasil

Tefelone: $18-36363249$

E-mail: fernando.chiba@unesp.br 